\title{
Alocação da força de trabalho em uma amostra do poder executivo brasileiro: levantamento dos custos e avaliação
}

\section{Heitor Silveira Freitas}

Tribunal de Contas da União - TCU, Brasília-DF, Brasil

\section{André Luiz Marques Serrano}

Universidade de Brasília - UNB, Brasília, DF, Brasil

\section{Lucas Oliveira Gomes Ferreira}

Tribunal de Contas da União - TCU, Brasília-DF, Brasil

Universidade de Brasília - UNB, Brasília, DF, Brasil

Sob a ótica da alocação adequada da força de trabalho, tem-se observado um problema crítico para as organizações, pois a variedade de fatores que o ensejam torna esse assunto complexo e de difícil gerenciamento. A busca pela produtividade exige cada vez mais do servidor, impactando tanto na necessidade do conhecimento dos custos quanto nas horas trabalhadas. Nesse sentido, esse impacto materializou-se mediante processos de racionalização e técnicas que incorporam novas tecnologias no entendimento da estrutura organizacional. A análise foi gerada por meio de um modelo de dimensionamento que considera a demanda como fator preponderante na decisão de alocar para atribuir os custos levantados sobre duas perspectivas: a partir do custo total com o quantitativo de servidores reais alocado e do quantitativo de servidores estimados pelo modelo de dimensionamento adotado. $O$ estudo tem por objetivo analisar o impacto da alocação da força de trabalho nos custos dos produtos gerados pelas pastas de três órgãos da administração pública federal direta com 22 áreas, que oferecem 571 entregas mapeadas a partir do trabalho de 689 servidores, e identificar que tipo de economia pode ser gerada a partir de uma adequada alocação de servidores. Por fim, movimentos internos da gestão podem contribuir para o resgate do equilíbrio das contas públicas e há possibilidade de formalizar e organizar entregas, mesmo as mais simples, a partir das inúmeras atividades de cada área, tornando a atividade estatal mais transparente e disponível para a sociedade.

Palavras-chave: dimensionamento, força de trabalho, custos no setor público 


\section{Asignación de la plantilla en una muestra de poder ejecutivo brasileño: elevación de costos y evaluación}

Desde la perspectiva de la adecuada asignación de la fuerza laboral, se ha observado un problema crítico para las organizaciones, debido a la variedad de factores que hacen que este tema sea complejo y difícil de manejar. La búsqueda de productividad demanda cada vez más del servidor, incidiendo en la necesidad de conocer los costos en cuanto a las horas trabajadas. En este sentido, este impacto se materializó a través de procesos de racionalización y técnicas que incorporan las nuevas tecnologías en la comprensión de la estructura organizacional. El análisis se generó mediante un modelo de dimensionamiento que considera la demanda como factor preponderante en la decisión de adjudicar los costos planteados desde dos perspectivas: desde el costo total con el número de servidores reales asignados y el número de servidores estimado por modelo de dimensionamiento adoptado. El estudio tiene como objetivo analizar el impacto de la asignación de la mano de obra sobre los costos de productos generados por las carpetas de tres dependencias de la administración pública federal directa con 22 áreas, que ofrecen 571 entregas mapeadas a partir del trabajo de 689 servidores, e identificar de qué tipo. Se pueden generar ahorros a partir de una asignación adecuada de servidores. Por último, los movimientos de gestión interna pueden contribuir a la recuperación del saldo de las cuentas públicas y existe la posibilidad de formalizar y organizar las entregas, incluso las más sencillas, en base a las numerosas actividades de cada ámbito, haciendo más transparente y accesible la actividad estatal para la sociedad.

Palabras clave: dimensionamiento, fuerza de trabajo, costos del sector público

\section{Allocation of the workforce in a sample of Brazilian executive power: lifting of costs and evaluation}

From the perspective of the adequate allocation of the workforce, a critical problem has been observed for organizations, since the variety of factors that make this issue complex and difficult to manage. The search for productivity demands more from the server, impacting on the need to know the costs regarding the worked hours. Hence, this impact materializes processes of rationalization and techniques that incorporate new technologies in the understanding of the organizational structure. The analysis was generated by means of a dimensioning model that considers demand as a preponderant factor in the decision to allocate to attribute the costs raised from two perspectives: from the total cost with the number of real servers allocated and the number of servers estimated by the sizing model adopted. The study aims to analyze the impact of the allocation of the workforce on the costs of products generated by the folders of three agencies of the direct federal public administration with 22 areas, which offer 571 deliveries mapped from the work of 689 servers, and to identify what type savings can be generated from an appropriate allocation of servers. Finally, internal management movements can contribute to the recovery of the balance of public accounts and there is the possibility of formalizing and organizing deliveries, even the simplest ones, based on the numerous activities in each area, making the state activity more transparent and available to the society.

Keywords: sizing, workforce staff, public sector cost 


\section{Introdução}

Os ambientes organizacionais estão em constante evolução, tornando cada vez mais complexa a alocação da força de trabalho e a mensuração do custo efetivo versus produtividade. Dessa forma, ambientes públicos veem-se pressionados a reagir rapidamente a tal evolução e a inovarem seu modus operandi. Isso exige ações ágeis e tomadas de decisão operacional frequentes, rápidas, estratégicas e, em muitas situações, táticas, algumas das quais bastante complexas. Para que tais decisões sejam tomadas, podem ser necessárias quantidades consideráveis de dados: financeiros, econômicos, gerenciais, entre outros, a fim de que se possam garantir informações e conhecimentos relevantes.

No que se refere às finanças públicas, no cenário de crise fiscal em que o Brasil está inserido desde o ano de 2013, fica cada vez mais complexo administrar a gestão e as contas estatais. Especificamente no Brasil, o setor público (União, estados e municípios) contava, em 2017, com um quadro de pessoal de quase 11,3 milhões (INSTITUTO DE PESQUISA ECONômicA ApLICAdA, 2019). Esse número representa 17,67\% dos 64,3 milhões de vínculos empregatícios do país. Em 2015, esse quantitativo representou 16\%, um percentual menor do que a média dos países membros da OCDE, que foi de 18,1\% para o mesmo ano (ORganização PARA A COOPERAÇÃo E DESENVOLVIMENTO ECONÔMICO, 2017).

Pela comparação com outros países, o tamanho da força de trabalho não parece ser um problema diferencial no Brasil, contudo, o valor da remuneração dos servidores e o gasto com pessoal da administração pública representa um desafio (BANCO MUNDIAL, 2017). A participação dos gastos de pessoal sobre o total da despesa ou sobre o total da receita no Brasil fica um pouco abaixo das médias da América Latina e da região do Oriente Médio e do Norte da África; quase se iguala à média da África; e é significativamente superior às médias encontradas na Ásia e na Europa. O mesmo estudo mostra que o setor público agregado (federal e subnacional) paga, em média, salários aproximadamente $70 \%$ superiores ( $R \$ 44.000$ por ano) aos pagos pelo setor privado formal ( $R \$ 26.000$ por ano), dados de 2017. Portanto, o desafio é criar alternativas que permitam a entrega de mais e melhores serviços públicos. Alguns exemplos a se considerar são o dimensionamento da força de trabalho (DFT) em bases 
científicas (EVEBORN; RöNNQVIST, 2004), a terceirização (SALVAdoR; RIBA, 2017) e a profissionalização das carreiras do setor público (CAVALCANTE; CARVALHO, 2017).

O dimensionamento da força de trabalho é a determinação de quantos trabalhadores são necessários para que uma organização entregue os objetivos e produtos para ela definidos. É imperativo que duas informações sejam extremamente debatidas dentro do setor público: quantos trabalhadores são necessários para a entrega de um determinado serviço ou produto à sociedade e quanto custa essa entrega, tendo em vista o principal insumo da administração pública: recursos humanos. Destarte, o problema de pesquisa é entender em que medida a força de trabalho de órgãos da administração direta federal está sendo eficientemente alocada, tendo como parâmetro uma avaliação a partir de gastos com pessoal (SERRANO, 2016).

Sendo assim, o objetivo desta pesquisa foi analisar o impacto da alocação da força de trabalho nos custos dos produtos gerados pelas pastas de três órgãos da administração pública federal direta: Controladoria-Geral da União (CGU), Advocacia-Geral da União (AGU) e Ministério da Economia (ME), com 22 áreas analisadas, 571 entregas mapeadas a partir do trabalho de 689 servidores. A amostra de servidores foi gerada randomicamente do total de servidores descritos a seguir: na CGU, 2.262 em 2016, 2351 em 2017 e 2301 em 2018; na AGU, 9.313 em 2016, 9.704 em 2017 e 10.062 em 2018; no Planejamento, 6.451 em 2016, 6.361 em 2017 e 6.229 em 2018. Por fim, esta pesquisa buscou identificar que tipo de economia pode ser gerada a partir de uma adequada alocação de servidores. Esse é um importante passo para que o serviço público deixe de ser visto como um espaço no qual os postos de trabalhos são mais valorizados pelas vantagens para seus ocupantes do que como um meio eficiente de oferecer serviços públicos de qualidade à sociedade. À vista disso, identificou-se uma lacuna de pesquisa voltada à compreensão dos reflexos que a alocação da força de trabalho pode gerar nas organizações públicas. Assim, o presente estudo apresenta como questão de pesquisa: qual é o impacto dos custos na alocação da força de trabalho no âmbito dos órgãos da administração pública?

O trabalho é composto, além desta introdução, por um referencial teórico focado no dimensionamento da força de trabalho. Em seguida, a metodologia descreve cada uma das três etapas realizadas para cumprir o objetivo da pesquisa. Posteriormente, os resultados são apresentados separadamente por cada uma das etapas realizadas, 
descrevendo cada um dos órgãos sob análise. Por fim, as considerações finais relatam as conclusões às quais foi possível chegar a respeito do dimensionamento da força de trabalho nos três órgãos analisados.

\section{Referencial teórico}

\subsection{Gestão eficiente nas organizações públicas e o dimensionamento da força de trabalho}

Como ferramenta de aprimoramento da gestão eficiente, são necessários modelos de dimensionamento da força de trabalho, que é um segmento do planejamento da força de trabalho, que, por sua vez, compõe a área gestão organizacional (AVELLANEDA; GoMES, 2015). Destarte, o dimensionamento compõe um processo de planejamento da força de trabalho (PFT), algo mais amplo (VIANNA, 2013). O planejamento da força de trabalho visa unir a necessidade de pessoal de uma divisão do governo com o que se dispõe de conhecimento e habilidades no quadro de pessoal. Mais do que definir o tamanho do quadro, o planejamento envolve a avaliação de competências (CHOUDHURY, 2007). É um processo de ajustamento entre o que a organização pretende entregar e qual a necessidade de capital humano, auxiliando a organização no enfrentamento de contingências e em uma atuação mais eficiente.

Na exploração de uma atuação mais eficiente, as organizações desenvolvem mecanismos de ajustes, ou seja, elaboram uma avaliação sistemática do conteúdo e da composição da força de trabalho de um governo para determinar quais ações o Estado precisa tomar para responder às demandas futuras para o atingimento de metas e cumprimento de objetivos organizacionais. Ademais, devem garantir que suas equipes estejam no lugar certo e tenham as habilidades adequadas para seu trabalho (JACOBSON, 2010). Por fim, o dimensionamento da força de trabalho é crucial para o fornecimento de níveis suficientes de serviços para cumprir as missões que o público espera do governo (Goodman; French; Battaglio, 2015). 
A análise de trabalho tem sido considerada como o processo de coletar, analisar e estruturar informações sobre os componentes de um trabalho e suas características, incluindo contexto ambiental e os próprios requisitos do trabalho (SANCHEZ; LEVINE, 2002). As razões para a análise do trabalho residem na necessidade de conhecer as tarefas a serem desempenhadas, preocupando-se em descrever as atividades a serem realizadas. Essa atividade é importante para a identificação de responsabilidades e definição de um sistema de gerenciamento de desempenho (MORGESON; FREDERICK; CAMPION, 2000).

De posse do que se deve entregar, a demanda, e da organização do tempo e das equipes, é possível calcular quantas pessoas são necessárias para entregar à organização o cumprimento de seus objetivos. Na mesma linha, Santos (1998) já definia DFT como a especificação quantitativa e qualitativa de pessoal a ser empregado na realização de determinada atividade, ou seja, é o número de profissionais qualificados necessários para tornar possível a realização de determinada tarefa. De forma mais objetiva, o DFT, dentro do planejamento da força de trabalho, é a definição do tamanho das equipes (HELTON; JACKSON, 2007; LI; CHEN; CAI, 2007; Dickinson; SullivAn; HeAD, 2015; Cunha et al., 2018).

No entanto, conforme relatado por Vianna et al. (2013), o número de publicações nacionais relativas ao tema de estimativas da força de trabalho é pequeno. Logo, a pesquisa nesse campo necessita de dedicação dos pesquisadores da área para aumentar a quantidade de trabalhos.

\subsection{Escolha racional como mecanismo de definição do número ótimo de trabalhadores}

O DFT entrelaça-se na teoria da escolha racional na medida em que busca definir o número ótimo de trabalhadores na busca pelo ponto ótimo de eficiência. Sendo assim, é uma parte do processo de otimização feito pelos tomadores de decisão a partir de análises de custo e de benefício da atuação organizacional para maximizar sua utilidade (MoLL; HOQUE, 2006). A escolha racional parte da premissa de que a melhor escolha requer uma boa análise da situação e das variáveis potencialmente influentes para nortear a decisão dos agentes no sentido de selecionar a melhor alternativa (RIBEIRO; LEITE; CROZATTI, 2006), aquela que maximize a satisfação de suas preferências e minimize o esforço empreendido. 
Complementando a teoria das escolhas racionais, a teoria da contingência mostra que as organizações são vivas e, consequentemente, dinâmicas. Os processos de DFT devem então acompanhar as mudanças nas organizações, adaptando-se a diferentes contextos. A teoria da contingência parte da premissa de que as condições do ambiente são o que causa as transformações no interior das organizações. A melhor forma de estruturar a organização depende de características situacionais com as quais a organização se depara. Sendo assim, não existe uma única e melhor forma de se organizar, a forma depende do tipo de tarefa e do ambiente interno da organização (GUERRA, 2007).

Destarte, o DFT relaciona-se assim a uma perspectiva calculadora do institucionalismo, partindo do fato de que o comportamento dos indivíduos ocorre a partir do cálculo estratégico a fim de maximizar a renda pessoal ao buscar minimizar os custos e maximizar os lucros pessoais, em detrimento do coletivo (MENDES; MARTINS; SERRANO, 2020).

\subsection{Inputs encontrados na literatura quanto ao processo de DFT}

Levantaram-se, em análise bibliométrica, os principais inputs encontrados na literatura quanto às informações necessárias para o processo de DFT: estratégia, estrutura, processos, pessoas e legislação. A discussão sobre informações requeridas coincide com a discussão sobre variáveis a serem utilizadas em um modelo de DFT, uma vez que aquela é a fonte deste. A dimensão pessoal refere-se a uma abordagem sobre o indivíduo; a dimensão resultados leva em conta aspectos de produção da organização; e a dimensão contexto refere-se à questão comportamental. Além do encaixe nas dimensões mencionadas, as variáveis podem ser classificadas quanto à tangibilidade de suas características, como variáveis hard e soft (PEREIRA, 2016).

Variáveis hard geralmente estão relacionadas a números, são mais fáceis de guardar e transmitir por maneiras impessoais, como eletronicamente. Esse tipo de variável, por ser mais objetivo, favorece a comparação. Outras vantagens das variáveis hard são: custo baixo de produção, são duráveis e são menos suscetíveis a perdas. Já as variáveis soft estão mais relacionadas a questões subjetivas, como o comportamento humano (LIBERTI; Petersen, 2019). Franco e Serrano (2018) admitem a possibilidade de quantificação de variáveis qualitativas soft, mas defendem que, por se tratar de um modelo utilizado para 
definir um número ideal de trabalhadores, a espinha dorsal do modelo deve considerar variáveis hard.

Assim sendo, o processo de DFT requer o uso de variáveis adequadas para uso no modelo, as quais podem ser retiradas de qualquer parte da organização e sob qualquer perspectiva. O funcionamento da organização pode ser visto sob a perspectiva de cadeia de valor ordenada do nível macro para o micro: macroprocesso, processo, atividade e entrega. Os processos são o conjunto de atividades realizadas em uma sequência lógica com o objetivo de produzir um bem ou serviço. As atividades são as partes do processo executadas por um departamento ou pessoa das quais resultam uma entrega, a qual é qualquer produto, resultado ou capacidade para realizar um serviço exclusivo e verificável que deve ser produzido para encerrar um processo, uma fase ou um projeto (GONÇALVES, 2000; Alvarenga-Netto, 2004; Torres et al., 2013; Sotille et al., 2016).

No dimensionamento da força de trabalho, os modelos são expressos a partir de variáveis que influenciam o quantitativo de pessoas necessárias. O trabalho de definição de variáveis é fundamental, pois, por se tratar de uma técnica que deve se adaptar às peculiaridades da organização, a subjetividade na seleção e elaboração pode prejudicar a qualidade do modelo. Os modelos de DFT, por se tratar de ferramenta de adequação de número de funcionários alocados para um determinado padrão de entrega, devem considerar informações relacionadas à produção e à disponibilidade do indivíduo no trabalho (HeLton; JACKSON, 2007; Dickinson; SUlLIVAN; HeAd, 2015). Associado aos elementos o que foi entregue e por quem, insere-se o fator esforço, que pode ser definido como o tempo gasto por cada funcionário em cada tipo de entrega (SERRANO; Franco, 2018).

Portanto, as hipóteses de pesquisa relacionadas ao DFT sugerem que os objetos ou departamentos analisados não se encontram no ponto ótimo da relação custo-benefício dos serviços prestados. Consequentemente, o DFT viabiliza calcular a quantidade ótima para alocação do esforço necessário para atingir a maximização desejada. 


\section{Metodologia}

O estudo dispôs de três etapas para cumprir seus objetivos. Na primeira, o foco foi um modelo de dimensionamento para definir o número ideal da força de trabalho por área em órgãos da administração direta federal. A segunda foi atribuir o custo da força de trabalho aplicada a cada entrega, tendo como base o quadro atual e ideal de servidores atribuído pelo modelo. A terceira buscou avaliar o desempenho em termos de produção, de força de trabalho e de custo da entrega através de análise fatorial.

Pelas variáveis observadas nos estudos levantados, podemos agrupá-las em entregas (serviços/bens ofertados), esforço de elaboração e disponibilidade de força de trabalho. Tais variáveis vão ao detalhe do objeto observado. No caso da entrega, a variável procura levantar seus tipos e a demanda por cada um. No caso do esforço, demonstra o percentual empregado de mão de obra por tipo de entrega. Por fim, para a disponibilidade de força de trabalho, percebe-se uma maior dedicação, evidenciando, a partir de variáveis, o quantitativo de funcionários, as movimentações ocorridas, as indisponibilidades e até a produtividade.

De posse das informações relacionadas ao que se pretende entregar, à disponibilidade da força de trabalho e ao nível de esforço empregado em cada entrega, é possível definir um quantitativo de trabalhadores que maximize a relação custo-benefício dos serviços prestados pela administração pública.

Em que pese a importância dispensada à ferramenta DFT e os benefícios já observados nas organizações que adotaram modelos de DFT, a administração pública brasileira ainda está em estágios iniciais de adoção de modelos de dimensionamento. Levantamento do Tribunal de Contas da União (TrIBUNAL DE CONTAS DA UNIÃo, 2018) demonstrou essa situação no âmbito da gestão de recursos humanos federal.

\subsection{Dos órgãos analisados}

O objeto de estudo é composto por três órgãos superiores da administração direta federal. Inicialmente, a Controladoria Geral da União (CGU), composta por cinco órgãos 
específicos que atuam na área finalística do ministério. Além dos órgãos singulares, o ministério também conta com dois órgãos colegiados de atuação transversal em temas estruturantes da administração pública. As áreas administrativas e de suporte ficam a cargo da Secretária Executiva, responsável também pela articulação dos vários assuntos tratados no órgão.

O segundo órgão superior foi a advocacia Geral da União (AGU), que possui atuação bem peculiar, pois tem uma parte de equipe atuando de forma centralizada; e outra, de forma descentralizada, com lotação em diversos outros órgãos. Sua estrutura conta com quatro grandes órgãos centrais, com atuações específicas e distintas e com carreiras também distintas. Dois outros órgãos centrais são responsáveis por normatizações relacionadas à sua atuação. Ademais, ela conta com um órgão consultivo responsável por questões relacionadas à atuação profissional dos membros das suas carreiras. A área administrativa fica a cargo de uma Secretária-Geral de Administração.

Por fim, o Ministério da Economia (ME), órgão que foi constituído pela fusão do Ministério da Fazenda e do Planejamento a partir de 2019, tendo sua estrutura organizacional alterada, mas a força de trabalho e sua composição em termos de cargos foram relativamente mantidas. As áreas que pertenciam ao antigo ministério foram transformadas em secretarias, mantidas as mesmas funções. Portanto, todos os valores atribuídos ao ME antes de sua criação dizem respeito aos valores do então Ministério da Fazenda. Portanto, os antigos ministérios da Fazenda e do Planejamento não foram considerados de forma isolada para viabilizar a comparabilidade com o ME nos estudos futuros. Nos últimos três anos, os órgãos contaram com seguintes orçamentos: 
Figura 1 | Orçamento dos órgãos de 2016 a 2018 (em milhões R\$̣)

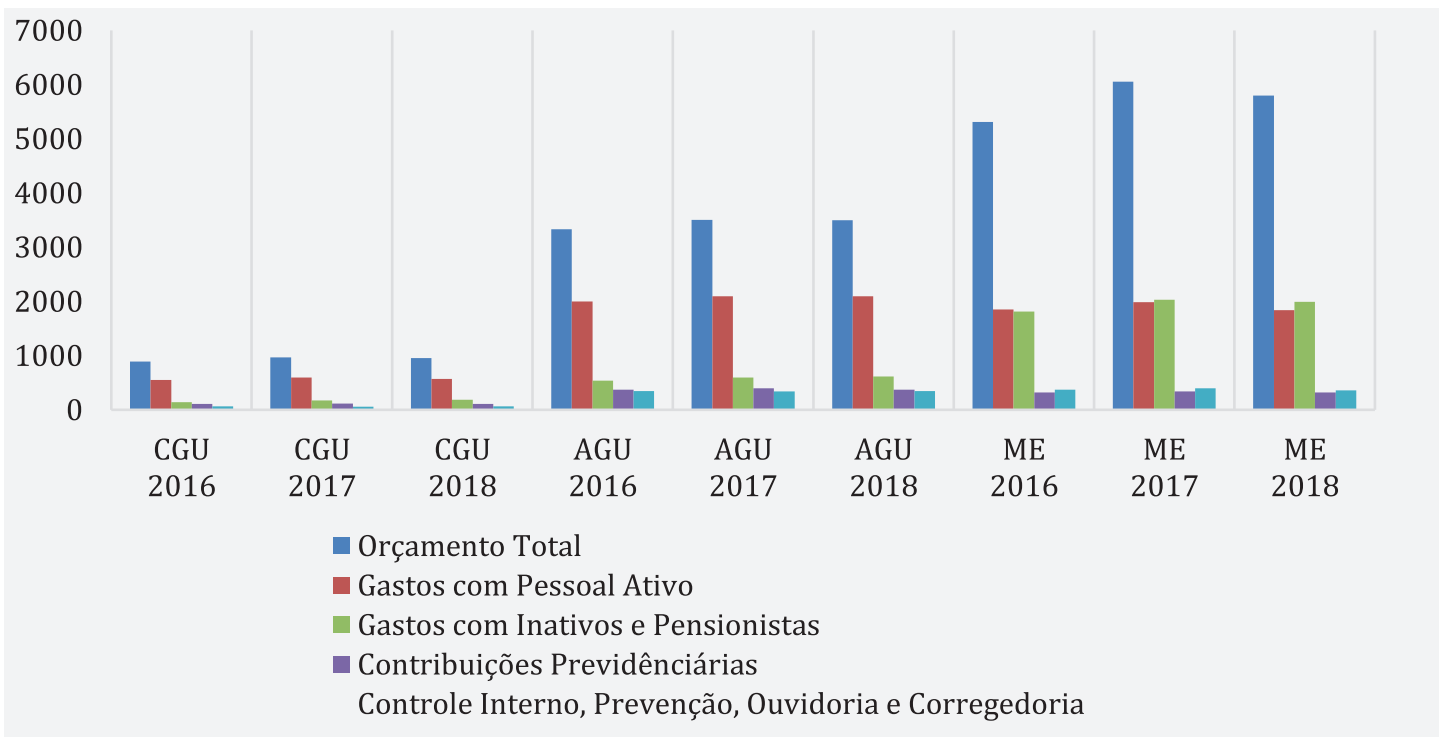

Fonte: Secretaria de Orçamento Federal (SOF).

A maior parte dos gastos da CGU e da AGU refere-se a gastos com pessoal, aproximadamente $60 \%$, o que se justifica por suas atividades principais envolverem principalmente a prestação de serviços para a própria administração pública. Diferentemente, os gastos com pessoal ativo do ME representam menos de $35 \%$ dos gastos da antiga pasta. Essa situação deve-se ao fato de essa organização ser responsável por inúmeras atividades de gestão e coordenação de toda administração pública federal, pelo elevado número de aposentados e pensionistas no órgão, além do fato de que essa pasta realiza transferências diretas a beneficiários de serviços públicos.

A Tabela 1 apresenta informações financeiras sobre as carreiras, tendo em vista se tratar de informações relevantes para avaliação de custos da força de trabalho. 
Tabela 1 | Remuneração das carreiras dos órgãos

\begin{tabular}{|c|c|c|c|c|c|c|}
\hline \multirow[b]{2}{*}{ Cargo } & \multicolumn{2}{|c|}{ CGU } & \multicolumn{2}{|c|}{ AGU } & \multicolumn{2}{|c|}{ ME } \\
\hline & R\$ Inicial & $\mathbf{R} \$$ Final & R\$ Inicial & R\$ Final & R\$ Inicial & R\$ Final \\
\hline \multirow{4}{*}{ Nível superior } & \multirow{4}{*}{$19.197,06$} & \multirow{4}{*}{$27.369,67$} & \multirow{4}{*}{$21.014,49$} & \multirow{4}{*}{$27.303,70$} & $21.014,49$ & $27.303,70$ \\
\hline & & & & & $19.197,06$ & $27.369,67$ \\
\hline & & & & & $14.782,16$ & $19.831,21$ \\
\hline & & & & & $5.739,09$ & $8.924,74$ \\
\hline \multirow{2}{*}{ Nível médio } & \multirow{2}{*}{$7.283,31$} & \multirow{2}{*}{$12.514,58$} & \multirow{2}{*}{$\begin{array}{lll}- & - \\
-1 & -1\end{array}$} & \multirow{2}{*}{ - } & $7.283,31$ & $12.514,58$ \\
\hline & & & & & $3.837,57$ & $4.514,23$ \\
\hline
\end{tabular}

Fonte: ME. 1: Cargo de nível superior ciclo de gestão A. 2: Cargo de nível superior ciclo de gestão B. 3: Cargo de nível superior infraestrutura. 4: Plano Geral de Cargos - nível superior. 5: Cargo de nível médio ciclo de gestão B. 6: Cargo de nível médio ciclo de gestão $B$.

As remunerações das carreiras da CGU e da AGU estão entre as melhores, o que torna a alocação eficiente uma prioridade para a gestão desses órgãos. As unidades analisadas na presente pesquisa têm como semelhança o fato de prestarem serviços para a administração pública, pelo menos em grande parte das suas atividades. Essas atividades são típicas de Estado e consideradas fundamentais para a gestão estratégica da administração pública federal.

\subsection{Caracterização dos Instrumentos de Pesquisa}

Na primeira etapa da pesquisa, foram utilizados questionários e realizados grupos focais para levantar informações sobre as atividades e as entregas de cada área dimensionada. As entregas foram levantadas a partir de reuniões e grupos focais com os servidores e suas respectivas chefias imediatas.

Os grupos focais podem ser definidos como pequenos grupos de pessoas reunidas para avaliar conceitos ou identificar problemas. O objetivo central do grupo focal é identificar percepções, sentimentos, atitudes e ideias dos participantes a respeito de um determinado assunto, produto ou atividade. Ademais, a sinergia entre os participantes leva a resultados que ultrapassam a soma das partes individuais (DIAS, 2000). 
Os questionários e os grupos focais foram realizados presencialmente, quando foram submetidas aos gestores e aos servidores dos órgãos analisados as demandas para o levantamento das entregas realizadas individualmente por cada servidor. Esse levantamento foi consolidado em um sistema de TI para viabilizar a análise das atividades realizadas pelos servidores alocados nos respectivos órgãos.

Com as entregas mapeadas, os esforços atribuídos por cada servidor em cada entrega foram levantados a partir de questionários. Esse instrumento de coleta consiste em um conjunto de questões com relação a uma ou mais variáveis a serem medidas (SAMPiere; Collado; Lucio, 2006; Chagas, 2000). O questionário também foi utilizado para a coleta de dados pessoais dos servidores com intuito de cruzamento de informações com as bases de dados da administração pública.

As informações sobre remuneração, carga de trabalho, ausências e outras que compõem registros necessários do órgão foram extraídas dos bancos de dados dos sistemas de informação de gestão de recursos humanos do Poder Executivo federal (Siape). Esses dados também foram utilizados para validação das informações oferecidas nos questionários e nos grupos focais.

\subsection{Procedimentos de Coleta e Análise de Dados}

O modelo escolhido foi o elaborado por Serrano e Franco (2018), a partir de deficiências encontradas em modelos anteriores, e aprimorado a partir de testes em organizações públicas (EVEBORN; RönNQVIST, 2004; TAYLOR et al., 2005; PERROCA; GAIDZINSKI, 1998; OliVEIRA; BIANCHINI; ABBADE, 2007).

O modelo trata o dimensionamento a partir de três dimensões: entrega, força de trabalho e esforço. Para cada dimensão foram atribuídas as variáveis a seguir caracterizadas. 
Tabela 2 | Variáveis utilizadas no modelo de dimensionamento

\begin{tabular}{|c|c|c|c|}
\hline Variável & Descrição & Variável & Descrição \\
\hline Qtd_servidores & $\begin{array}{l}\text { Quantidade de servidores } \\
\text { lotados na área dimensionada }\end{array}$ & feriados & Índice de feriados \\
\hline $\begin{array}{l}\text { Qtd_servidores_ } \\
\text { dime }\end{array}$ & $\begin{array}{l}\text { Quantidade de servidores } \\
\text { considerados no } \\
\text { dimensionamento }\end{array}$ & ictsj & $\begin{array}{l}\text { Índice de cobertura } \\
\text { técnica de ausências }\end{array}$ \\
\hline Esforc_total & $\begin{array}{l}\text { Esforço total disponível por } \\
\text { área }\end{array}$ & valor_kj_maior & $\begin{array}{l}\text { Nível de complexidade } \\
\text { da atividade }\end{array}$ \\
\hline Esforc_alocado & $\begin{array}{l}\text { Esforço empregado em } \\
\text { entregas }\end{array}$ & valor_mj & $\begin{array}{l}\text { Número de entregas } \\
\text { diárias }\end{array}$ \\
\hline Custo_total & $\begin{array}{l}\text { Custo total de servidores } \\
\text { lotados na área }\end{array}$ & valor_pj & Tempo produtivo \\
\hline Custo_alocado & $\begin{array}{l}\text { Custo de servidores } \\
\text { efetivamente em entregas }\end{array}$ & valor_pj_maior & $\begin{array}{l}\text { Nível de eficiência da } \\
\text { produção }\end{array}$ \\
\hline Custo_dime & $\begin{array}{l}\text { Custo de servidores calculado a } \\
\text { partir do dimensionamento }\end{array}$ & $\begin{array}{l}\text { valor_q_ } \\
\text { estimado }\end{array}$ & Jornada média \\
\hline Qtd_entrega & $\begin{array}{l}\text { Número de entregas unitárias } \\
\text { realizadas }\end{array}$ & valor_q_real & $\begin{array}{l}\text { Quantidade de } \\
\text { servidores real adaptada }\end{array}$ \\
\hline Absenteismo & Índice de absenteísmo & valor_tj & Jornada média \\
\hline Ativ_educativas & Índice de atividades educativas & valor_tj_maior & $\begin{array}{l}\text { Nível de produtividade } \\
\text { diária }\end{array}$ \\
\hline
\end{tabular}

Fonte: elaborado a partir de Serrano e Franco (2018).

A construção do modelo parte da premissa de que o dimensionamento da força de trabalho considera a produção e a capacidade produtiva das unidades organizacionais. Dito isso, o aumento da capacidade de produzir deve diminuir o quantitativo ideal de pessoal, conforme a equação 1:

$$
Q_{i}=\frac{\operatorname{Ln}\left(T_{i}\right)}{\operatorname{Ln}\left(P_{i}\right)} \times q_{i}
$$


Onde: Qi é a quantidade ideal de pessoas; Ti é um indicador de produtividade diária; Pi um indicador de eficiência da produção; e qi é a média histórica da quantidade de pessoas. $\mathrm{O}$ i representa a unidade dimensionada.

Para Serrano e Franco (2018), como $T_{i}$ e $P_{i}$ são indicadores, eles precisam ser mais detalhados. Sendo assim, a equação 2 considera a produtividade diária:

$$
T_{i}=\frac{k_{i} X m_{i} X I C T S_{i}}{t_{i} \times p_{i}} \times e^{k_{i}} \times I C T S_{i}
$$

Onde: $k_{i}$ é o efetivo pontual médio das atividades na escala $\left\{k_{i} \in R: 0 \leq k_{i} \leq 1\right\} ; m_{i}$ é o número de entregas diárias; ICTS é o índice de cobertura técnica de segurança para a cobertura das ausências ao serviço; $t_{i}$ é a jornada média de trabalho; $p_{i}$ é o percentual de tempo produtivo; e $K_{i}$ é o efetivo pontual médio das atividades na escala $\left\{K_{i} \in R: 0 \leq K_{i} \leq\right.$ 100\}. Já o indicador de eficiência da produção é definido na equação 3:

$$
P_{i}=\frac{e^{t_{i} \times k_{i \times q_{i}}}}{\sqrt{p_{i}}}
$$

Onde: $q_{i}$ é a média histórica da quantidade de pessoas; $t_{i}$ é a jornada média de trabalho; $k_{i}$ é o efetivo pontual médio das atividades na escala $\left\{k_{i} \in R: 0 \leq k_{i} \leq 1\right\}$; e $p_{i}$ referese ao percentual de tempo produtivo. Para tais indicadores, são englobados ainda outros dois importantes indicadores, sendo o primeiro explicitado na equação 4:

$$
k_{i}=\frac{\left(\ln \frac{\frac{\sum_{i=1}^{n i} \frac{m_{j i}}{h_{j i}}}{n_{i}}}{m_{i}} \times q_{i} \times 100\right)}{100}
$$

Onde: $m_{\mathrm{ji}}$ é o número de entregas; $h_{\mathrm{ji}}$ é a dedicação diária em horas para a realização das entregas; $n_{i}$ é o número total de diferentes entregas feitas; $m_{i}$ é a quantidade de entregas diárias; e $q_{i}$ é a média histórica da quantidade de pessoas. O subscrito i representa 
a unidade dimensionada e o subscrito j, as diferentes entregas da unidade. Já o segundo indicador é definido na equação 5:

$$
\operatorname{ICTS}_{j}=\left(\frac{\ln \left(\left\{\left[\left(1+\frac{f}{D-f}\right) \times\left(1+\frac{v_{j}}{d-v_{j}}\right) \times\left(1+\frac{\sum_{i} \quad a_{j i}}{D A}\right)\right]-1\right\} \times 100\right)}{\ln (100)}\right)+1
$$

Onde: $f$ é a quantidade de dias feriados no mês; $D$ é a quantidade total de dias no mês (igual a 30); $v_{i}$ é a quantidade de dias de ausência devido às atividades educativas da unidade; $d$ é a quantidade média de dias úteis por mês (igual a 21); $a_{\mathrm{ji}}$ é o somatório dos dias médios de ausências previstas; e DA é a quantidade total de dias de ausência possíveis considerando cada tipo de ausência j.

O modelo foi testado em órgão da administração federal (SERRANO; FRANCO, 2018), sendo comparado com o modelo de Gaidzinski (1998) e com a alocação real. Os resultados mostraram que o modelo dos autores atendeu a todos os pressupostos e que gerou resultados mais econômicos, atendendo a diversas expectativas empíricas e teóricas. Estudo semelhante foi realizado por Serrano et al. (2017), que testaram versão anterior do modelo.

Inicialmente, uma das vantagens do modelo testado foi suportar melhor variação do índice de cobertura técnica de segurança ao utilizar uma transformação logarítmica e um índice que é relativo ao máximo de ausência de trabalho que se poderia observar. Em segundo lugar, ao utilizar o tempo efetivo de trabalho e a complexidade da realização desse trabalho para estimar a produtividade, o método representou melhor as atividades humanas, dada a impossibilidade biológica de o ser humano de ter alto desempenho em toda a sua atividade profissional. Por fim, a fórmula desenvolvida pode ser aplicada a qualquer organização de qualquer natureza, desde que se controlem as variáveis indicadas.

$\mathrm{Na}$ análise fatorial por componentes principais, utilizada nesta pesquisa, foram extraídos os fatores a partir de uma matriz de correlação de Pearson, método também conhecido como transformação de Karhunen-Loève. Dito isso, um fator pode representar a combinação linear das variáveis originais da seguinte forma, equação 6: 


$$
\mathrm{F}_{j}=\sum \quad S_{i j} X_{i}
$$

Onde: $F_{j}$ são os fatores comuns não relacionados; $S_{i j}$ são os coeficientes dos escores fatoriais; e $X_{i}$ são as variáveis originais. $O$ score fatorial é um número resultante da multiplicação dos coeficientes pelo valor das variáveis originais. Quando existe mais de um fator, o escore fatorial representa as coordenadas da variável em relação aos eixos, que são os fatores (CORRAR et al., 2017). Os escores fatoriais são elaborados a partir dos autovetores e dos autovalores da matriz de correlação. Para adoção da técnica de transformação, são necessárias verificações de significância global, que, no caso deste estudo, serão feitas a partir da estatística de Kaiser-Meyer-Olkin (KMO) e pelo teste de esfericidade de Bartlett. Dessa forma, para a aceitação do modelo, é necessário que a matriz de correlação apresente valores elevados e estatisticamente relevantes.

O teste de esfericidade consiste em comparar a matriz de correlação de Pearson com a matriz identidade de mesma dimensão. Se a diferença entre os valores correspondentes fora da diagonal principal de cada matriz não for estatisticamente diferente de 0 , a determinado nível de significância, pode-se considerar que a extração dos fatores não será adequada. Dessa forma, pode-se estabelecer um teste de hipóteses da seguinte maneira:

$$
\begin{aligned}
& \mathrm{H}_{0}: \quad \rho=I \\
& \mathrm{H}_{1}: \quad \rho \neq I
\end{aligned}
$$

Já o teste KMO fornece a proporção de variância considerada comum a todas as variáveis na amostra em análise, ou seja, que pode ser atribuída à existência de um fator comum. Essa estatística varia entre 0 e 1 , sendo que valores mais próximos de 0 representam correlações de Pearson baixas entre as variáveis, que, por conseguinte, indicam uma análise fatorial imprópria. 
Assim sendo, a presente pesquisa se enquadra em uma análise fatorial exploratória, uma vez que não se parte de nenhuma pré-concepção das variáveis estudadas. Além disso, é uma análise fatorial $\mathrm{R}$, pois o objetivo é o agrupamento de variáveis a partir de relações de interdependências. As variáveis utilizadas mesclam características de produção, força de trabalho e custo da força de trabalho, sendo algumas delas fundamentais, inclusive, na elaboração do modelo de dimensionamento. Dessa forma, a determinação dessas variáveis teve como fundamento os pressupostos estabelecidos por Serrano e Franco (2018).

\section{Resultados e discussões}

Considerando o objeto da pesquisa, foram realizadas coletas de informações sobre entrega e esforço com 689 servidores. Para o levantamento de custo de cada área, foram considerados dados de remuneração de 729 servidores, visto que nem todos os servidores foram considerados alocados nas entregas mapeadas. Além disso, foram analisados dois conjuntos de documentos: os relativos ao processo de DFT (relatórios, atas e documentos de suporte ao processo de DFT) e os relacionados às extrações de dados fornecidos pelas áreas de TI.

\subsection{Número ideal da força de trabalho}

O conjunto e a quantidade de entregas realizadas completam o conhecimento da demanda ou a análise do trabalho. Na CGU, foi dimensionada uma unidade organizacional, com seis áreas subordinadas, todas elas áreas finalísticas do órgão.

Foram analisadas 158 entregas distintas realizadas por 327 servidores, representando mais de $15 \%$ da força de trabalho do órgão. Como foram dimensionadas áreas que prestam serviços semelhantes, com apenas mudança de clientela de atendimento, algumas entregas são comuns a todas as áreas.

Foram definidas entregas que vão desde a simples digitalização de um documento à elaboração de relatórios de controle e diagnósticos de políticas públicas federais. A amplitude do esforço encontrada para o rol de entregas foi elevada, com rotinas 
automatizadas, que requerem apenas ações humanas pontuais, sendo mapeadas com o consumo de apenas alguns minutos em sua execução; havia ainda outras rotinas, mais duradouras mais complexas e que envolviam mais pessoas, sendo mapeadas com o consumo de mais de mil horas da equipe.

No geral, as entregas da CGU consomem em média 153 horas para sua conclusão. Das 151 entregas mapeadas, 80\% consomem até 202 horas de trabalho, o que representa até quase dois meses de um único servidor alocado em tempo produtivo. Contudo, algumas atividades chegam a consumir até 1600 horas, geralmente correspondendo às atividades executadas em equipes ao longo de vários meses. São exemplos desse tipo de entrega os relatórios de grupos de trabalho, as edições normativas, as manualizações de procedimentos, entre outras.

Figura 2 | Horas gastas em cada entrega - CGU

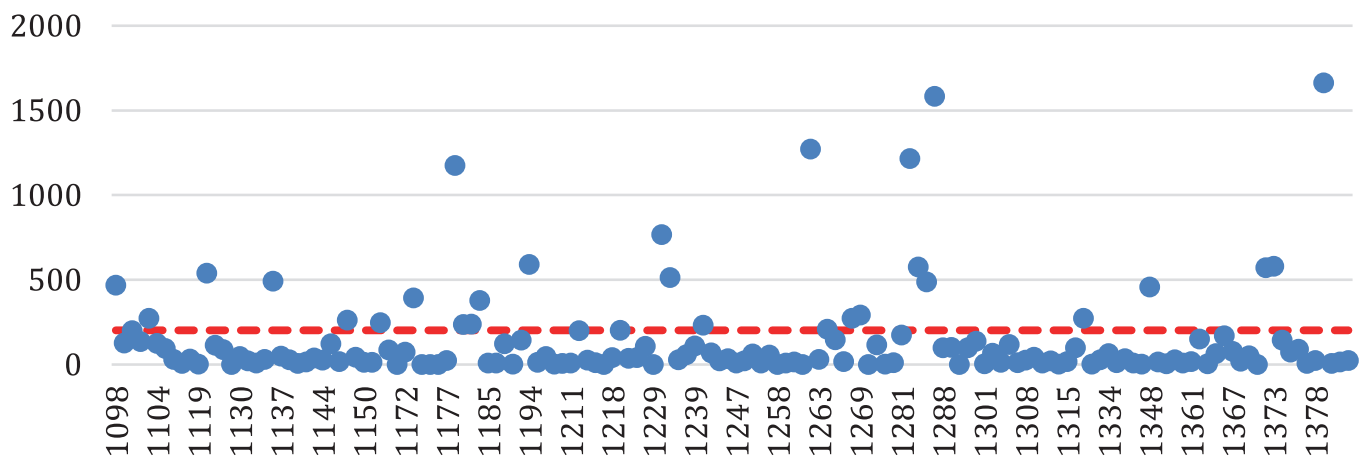

Fonte: elaborado pelos autores.

Embora exista uma grande amplitude nos níveis de esforço empregado nas entregas mapeadas, algumas, por exigirem bem mais esforço, acabam por concentrar boa parte da força de trabalho das áreas. No caso da CGU, por exemplo, mais de 50\% do esforço das áreas são concentradas em apenas 13 (8\%) entregas. Outra constatação é que existe uma tendência de que, quanto menor o esforço necessário, maior a quantidade de realizações da entrega. 
Figura 3 | Comparação esforço e horas dedicadas a entregas - CGU (em escala logarítmica)

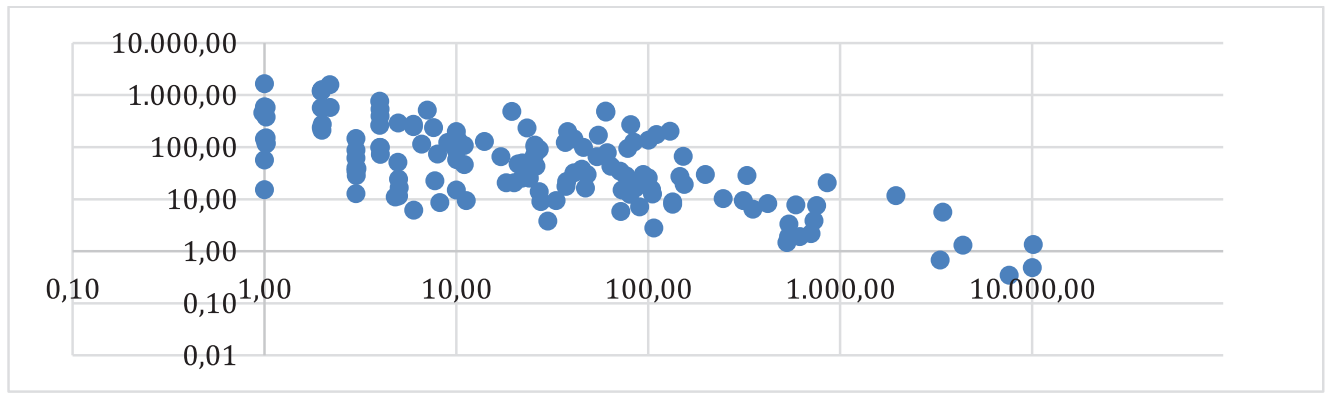

Fonte: elaborado pelos autores.

A Figura 3 nos mostra que as áreas, embora possuam seus esforços concentrados em algumas atividades específicas, possuem atividades mais simples que são reincidentes. Das horas produtivas, 63\% foram alocadas nas entregas mapeadas. Nesse cálculo, só foi considerada a carga de trabalho dos servidores que foram inseridos na base de mapeamento de esforço. É possível que o percentual de alocação de esforço seja distinto do percentual de custo excedente em decorrência da não alocação. Essa situação repercute no custo das entregas realizadas, como será visto na seção de análise do custo da entrega. Ademais, é possível perceber uma queda significativa no número de entregas realizadas nos dois anos analisados, que pode ser justificada pela redução de alocação de esforço nas entregas mapeadas.

No caso da AGU, a média de tempo gasto nas entregas mapeadas foi de 46 horas, o que demonstra atividades mais curtas mapeadas na AGU. Aproximadamente $80 \%$ das atividades consomem até 49 horas. Isso se justifica em parte por se tratar de entregas relacionadas a áreas de suporte do órgão, com características mais rotineiras e de apoio. 
Figura 4 | Horas gastas em cada entrega - AGU

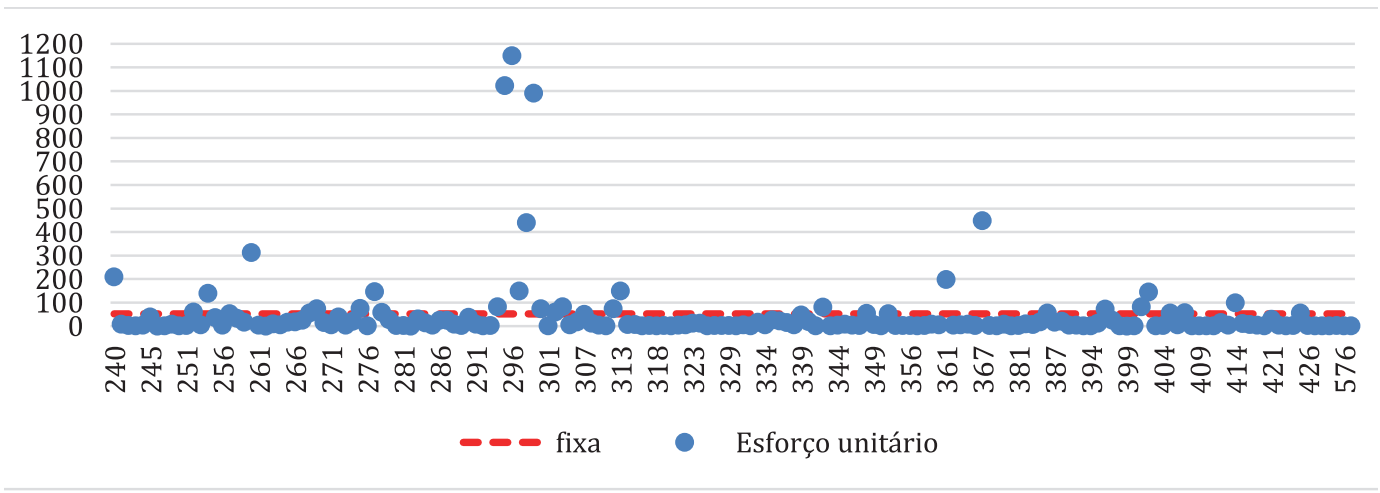

Fonte: elaborado pelos autores.

Por se tratar de atividades mais curtas e cotidianas, a quantidade de entregas é mais elevada. Muitas atividades das áreas mapeadas se referem à elaboração, digitalização e tramitação de documentos, por exemplo. Dessa forma, nos três anos analisados a média de quantidade de entregas realizadas foi superior a 4700 unidades. Se forem consideradas digitalizações de documentos feitas por uma determinada área, essa média fica muito superior. Para a AGU, 48 (28\%) entregas absorveram $80 \%$ do esforço das áreas envolvidas.

Nas áreas mapeadas também foi observada uma correspondência negativa entre esforço e quantidade de atividades realizadas por entrega. O total de $78 \%$ da força de trabalho foi passível de ser alocado nas entregas mapeadas. O ano de 2018 chamou a atenção pelo seu percentual de não alocação comparado com os anos anteriores, o que impactou na quantidade de entregas nesse ano. 
Figura 5 | Comparação esforço e horas dedicadas a cada entrega - AGU (horas em milhões)

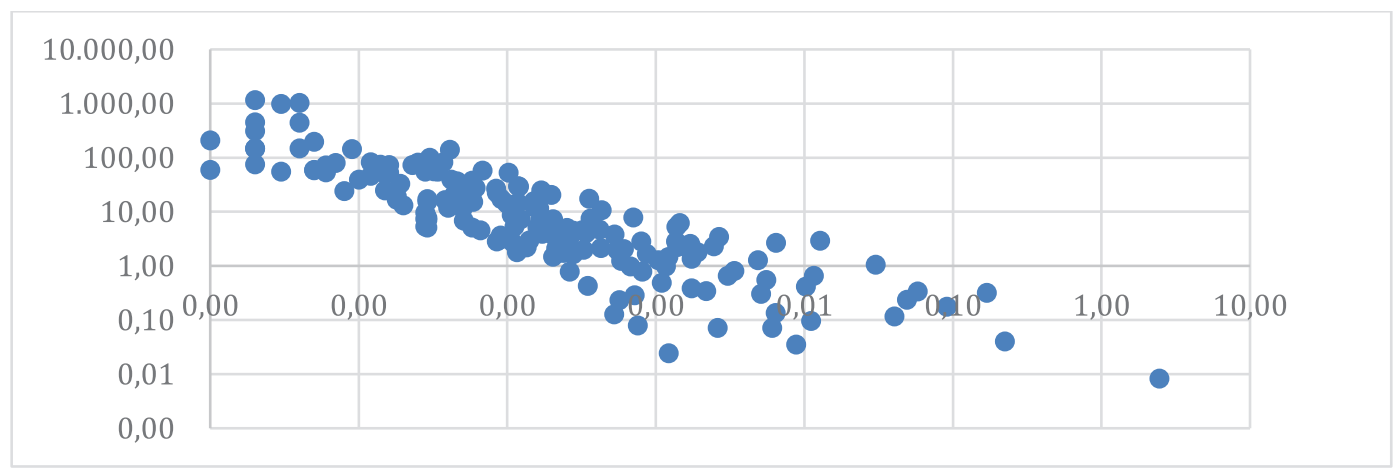

Fonte: elaborado pelos autores.

A redução do emprego de esforço nas atividades mapeadas no ano de 2018 provocou queda de $40 \%$ na quantidade de entregas realizadas. Cabe ressaltar que, de 2017 para 2018, a capacidade em esforço das áreas mapeadas não sofreu modificação tão relevante, sendo reduzida em $7 \%$, o que demonstra que a redução da quantidade está relacionada principalmente à redução da quantidade de esforço alocado às entregas mapeadas.

Quanto ao ME, foram dimensionadas duas unidades organizacionais, uma da área finalística e uma da área meio, com sete áreas subordinadas, todas finalísticas do órgão. Foram analisadas 107 entregas realizadas por 182 servidores, representando algo em torno de $3 \%$ da força de trabalho total do órgão. O esforço aplicado nas entregas foi em média de 63 horas, parecido com o levantamento gerado na AGU, porque a maior parte das entregas mapeadas foi de atividades cotidianas das áreas de suporte. Mais de $80 \%$ das entregas mapeadas consomem até 24 horas para sua conclusão. Ou seja, são atividades de natureza ainda mais curtas do que as do órgão anteriormente analisado.

À semelhança do que ocorreu com a AGU, como as atividades são mais curtas e rotineiras, a quantidade de entregas realizadas foi elevada; na média, foram realizadas mais de 2.334 entregas por tipo, desconsiderando para esse efeito atividades de atendimento, que somaram mais de 421 mil ocorrências. No caso do Ministério, não foi observada uma tendência inversa entre nível de esforço e quantidade de entregas realizadas. 
Figura 6 | Horas gastas em cada entrega - ME

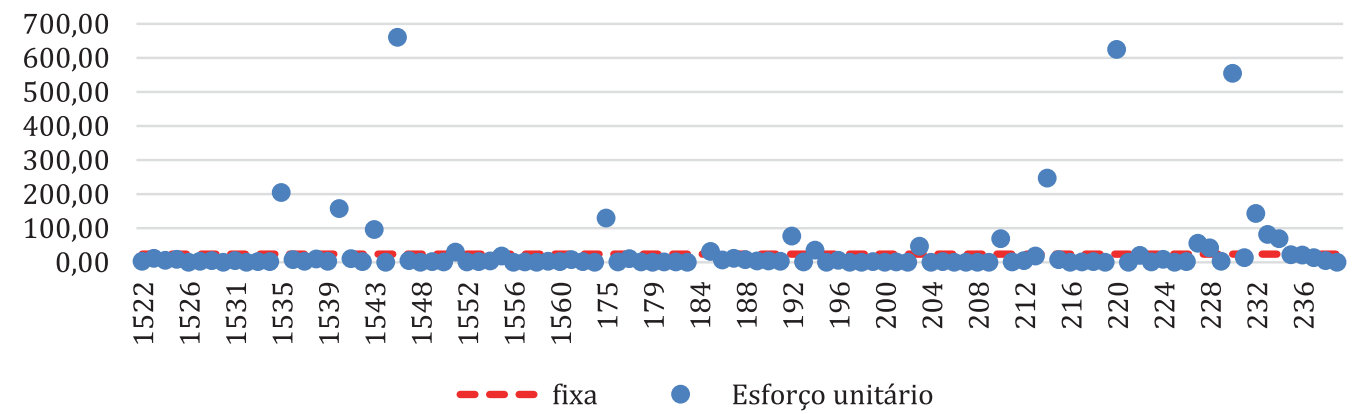

Fonte: elaborado pelos autores.

Quanto à alocação das horas disponíveis, o último órgão analisado apresentou situação distinta, com servidores não lotados na área mapeada sendo listados como colaboradores em entregas. Dessa forma, o número absoluto de servidores alocados para algumas áreas foi superior ao número de servidores lotados no respectivo setor. Quanto à alocação da força de trabalho, a unidade apresentou-se com melhor percentual de atribuição da sua capacidade em entregas definidas. Nesse órgão, 99\% das horas disponíveis foram atribuídas a entregas. Foi observado que a comparação entre esforço e quantidade de entregas realizadas ficou prejudicada em virtude da variação da quantidade de áreas dimensionadas nos três anos. Analisando apenas 2016 e 2017, considerando apenas as áreas mapeadas em comum, houve um aumento da quantidade de entregas no montante de $6 \%$, condizente com a manutenção da disponibilidade de esforço das áreas nesses anos, que foi acrescida apenas de 1,2\% em termos de capacidade.

A pesquisa mapeou 22 áreas que compõem as atividades de três grandes ministérios que prestam serviços de Estado. Foram 571 entregas mensuradas e analisadas, realizadas por 690 profissionais, analisados nos anos de 2016 a 2018. A parte possível de dimensionar já pode dar uma perspectiva dos ganhos em termos de racionamento de recursos que uma ferramenta de definição de força de trabalho pode oferecer.

A conclusão com essa etapa de mapeamento de entregas e de alocação de servidores é de que é possível transformar as atividades executadas nos setores em entregas bem definidas e observáveis. O levantamento provou a possibilidade de envolver em um processo de dimensionamento, nos três anos analisados, mais de 95\% dos servidores lotados nas áreas pesquisadas. Portanto, grande parte das atividades realizadas dentro 
das áreas é passível de organização em entregas definidas. Outra constatação relevante refere-se ao número de entregas distintas definidas em cada área, o que demonstra a diversidade dos serviços realizados em cada uma e seus diferentes níveis de complexidade.

As entregas e o estudo de seu comportamento ao longo do ano definem a demanda por determinado serviço, que é a premissa para o adequado dimensionamento da força de trabalho. O resultado da alocação em horas em cada um dos órgãos e do custo médio das horas é apresentado a seguir:

Tabela 3 | Comparação horas disponíveis dos órgãos

\begin{tabular}{|l|c|c|c|}
\hline Carga horária considerada & CGU & AGU & ME \\
\hline Quantidade de horas total & $1.279 .542,86$ & $795.514,29$ & $643.911,43$ \\
\hline Quantidade de horas produtiva & $767.725,71$ & $477.308,57$ & $386.346,86$ \\
\hline Quantidade de horas alocadas & $480.016,55$ & $475.637,14$ & $385.916,40$ \\
\hline Custo médio das horas (R\$) & 392,77 & 121,53 & 103,58 \\
\hline
\end{tabular}

Fonte: elaborado pelos autores.

No caso CGU, por exemplo, no qual a carreira que a compõe recebe salários superiores a $\mathrm{R} \$ \mathbf{2} 20$ mil mensais, entregas que parecem meramente procedimentais ficam custosas. Nos outros órgãos, em que não há salários tão altos, mas consideráveis, em média superiores a R\$ 8 mil, também aparecem casos semelhantes. Tal fato decorre de o custo médio da hora de cada órgão ser elevado.

\subsection{Dos custos da força de trabalho}

Em 2017 e 2018, na CGU, mais de R\$ 81,9 milhões (43,5\%) foram gastos com servidores não alocados em nenhum serviço específico. Tendo em vista que seus serviços são mais longos e são executados por servidores de carreira, que têm horas de trabalho mais custosas, o custo de cada entrega mapeada foi elevado, com o salário médio mensurado de aproximadamente $\mathrm{R} \$ 23.336,62$. A atividade que mais absorveu custos na CGU no período analisado foi a elaboração de relatórios de auditoria. Para essa entrega, foram elaborados cerca de 60 relatórios de auditoria a um custo de R\$ 11,5 milhões. Embora a duração e a quantidade de pessoas envolvidas nas entregas justifiquem seu elevado custo, existe um excedente decorrente de servidores lotados e não alocados nas entregas mapeadas. 
Figura 7 | Comparação de custos unitários das entregas da CGU

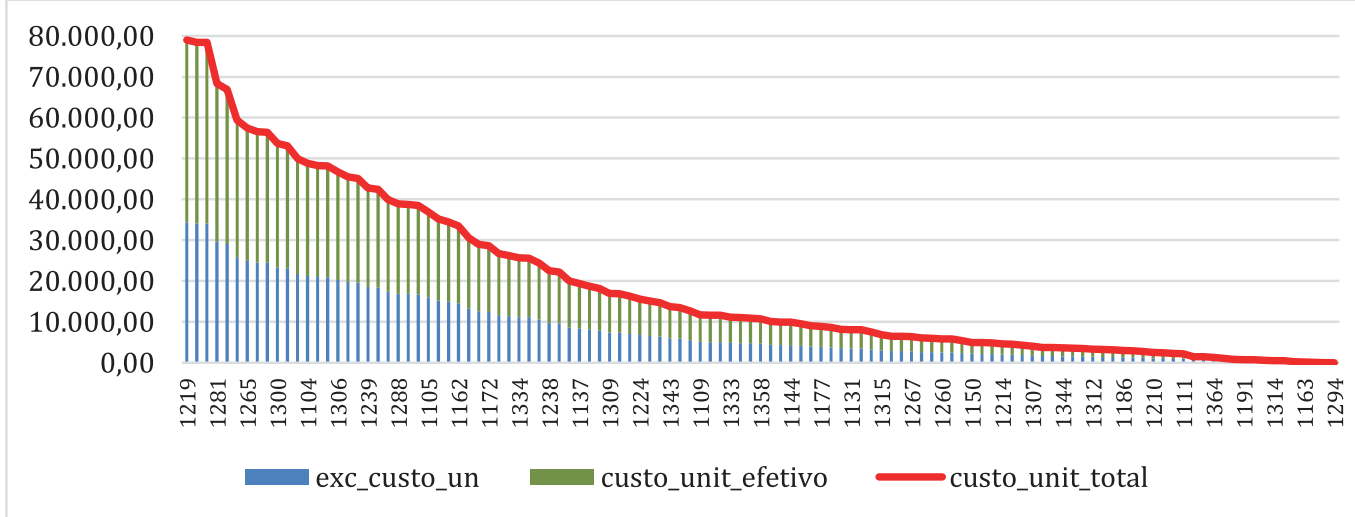

Fonte: elaborado pelos autores.

Esse excedente de custo surge antes mesmo de uma análise de compatibilidade de quadro real e quadro estimado de servidores, a partir do uso de um modelo de dimensionamento. No caso do custo unitário excedente das áreas, a média foi de R\$ 26.127. Considerando até $80 \%$ das entregas, esse excedente foi de até $\mathrm{R} \$ 34.596$. A partir da constatação de eventuais servidores não alocados nas principais entregas da área, já é possível identificar possibilidade de redimensionamento de força de trabalho.

No caso da AGU, a não alocação de servidores pesou menos na avaliação dos custos das entregas realizadas, uma vez que nesse órgão o percentual de servidores não alocados integralmente em atividades mapeadas como entrega foi menor. Por se tratar de entregas mais relacionadas a atividades de suporte, os custos da força de trabalho empregados nas entregas mapeadas foram bem menores dos que os examinados na CGU, em virtude de o esforço médio empregado em cada entrega ser menor e do menor salário médio dos servidores das áreas. Na AGU, a média de salários recebidas nos três anos examinados foi de aproximadamente $\mathrm{R} \$ 8.500,00$.

A média de custo por unidade de entrega realizada foi de $\mathrm{R} \$ 5.741$. No caso desse órgão, 48 tipos de entregas (28\%) consumiram até $80 \%$ dos recursos totais das áreas. As atividades são mais curtas e menos custosas do que as mapeadas na CGU; contudo, ainda foi possível perceber custo excedente em virtude de alocação de servidores em atividades residuais. 
Figura 8 | Comparação de custos unitários das entregas da AGU

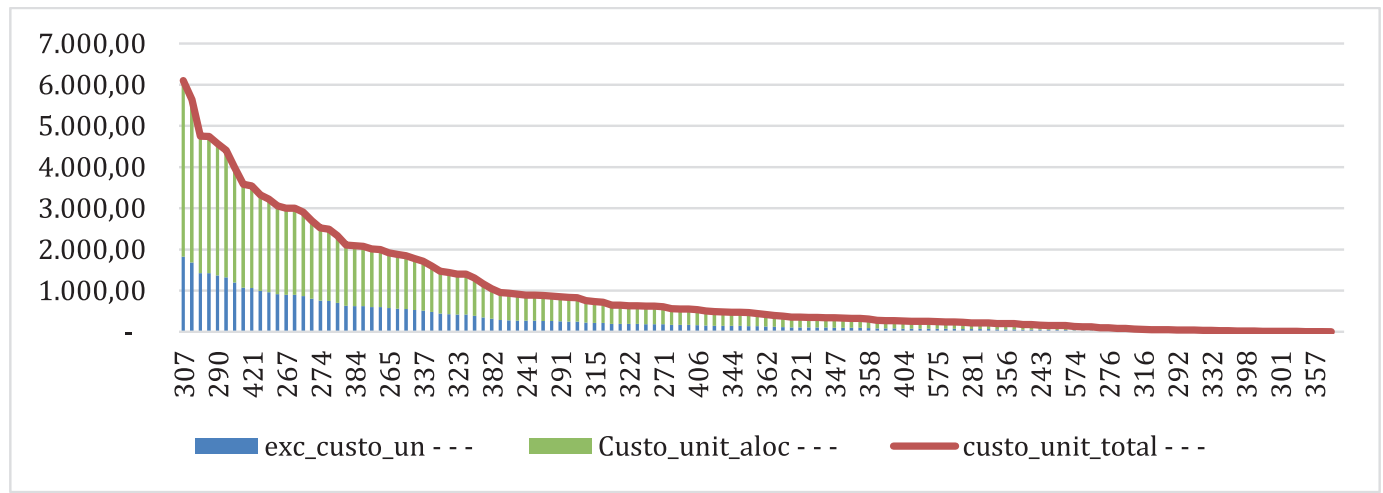

Fonte: elaborado pelos autores.

Além de abarcar um período maior, três anos, o excedente foi menor do que o encontrado na CGU. Contudo, 30\% de excedente, em virtude de servidores alocados em atividades incrementais, ainda é uma participação relevante e fornece indícios de que, quando a análise de dimensionamento da força de trabalho for inserida, esse excedente pode ser ainda maior. No caso do custo unitário excedente das áreas da AGU, a média foi de $R \$ 1.717$. Considerando até $80 \%$ das entregas, esse excedente foi de até $R \$ 1.903$.

Finalmente, no ME as atividades foram as mais curtas em termos de esforço empregado. Além disso, nesse órgão, a média de salário foi mais baixa que nos dois outros, levando, por consequência, o custo das entregas mapeadas a custos menores em termos de força de trabalho empregada.

Em termos de custo de força de trabalho alocado, teve comportamento similar ao encontrado na AGU, tendo em vista a natureza das atividades mapeadas serem similares e o nível salarial dos servidores serem próximos. Na média, os salários recebidos nos três anos analisados foram de $\mathrm{R} \$ 8.422,71$.

As entregas mapeadas desse órgão custaram $\mathrm{R} \$ 6.534,00$. Contudo, alguns serviços nesse órgão elevaram a média. Considerando outra medida de dispersão, observou-se que $80 \%$ das entregas custaram até 2.478,69.

No caso do $\mathrm{ME}$, as entregas que mais absorveram recursos estão relacionadas ao atendimento a servidores ou à prestação de serviços de informações a outras áreas. A entrega que mais absorveu recursos foi informações concedidas à Consultoria Jurídica 
do órgão, que absorveu $\mathrm{R} \$$ 2,1 milhões em 162 entregas realizadas. O ME foi o órgão que menos apresentou custos não alocados a atividades passíveis de definição como entregas, menos de $20 \%$ nos três anos analisados.

\section{Figura 9 | Comparação de custos unitários das entregas do ME}

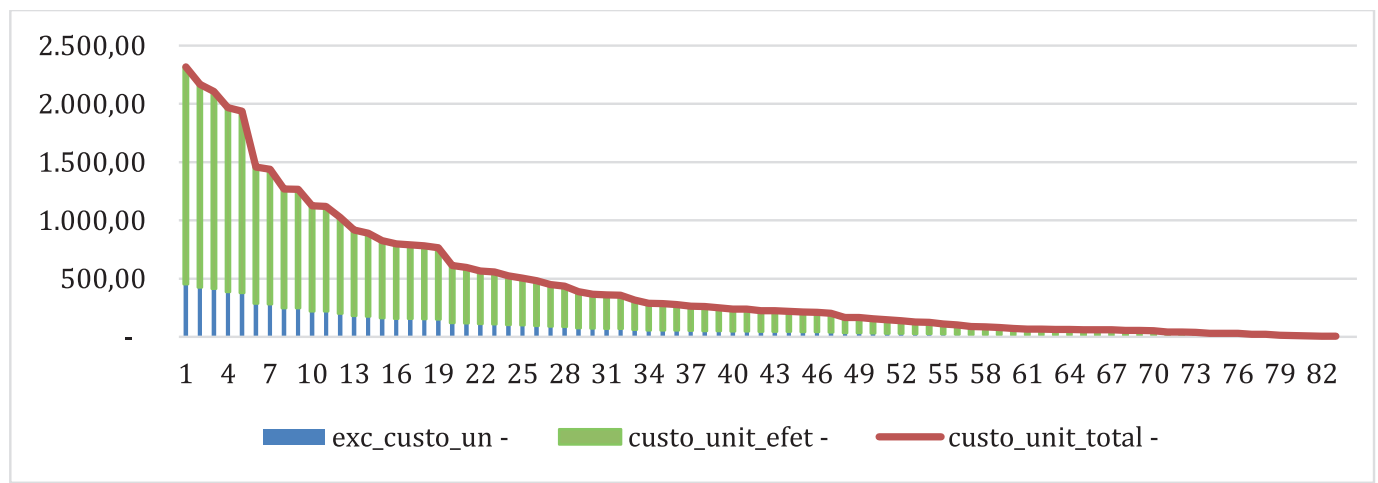

Fonte: elaborado pelos autores.

No caso do custo unitário excedente das áreas do ME, a média foi de $\mathrm{R} \$ 1.275$. Considerando até $80 \%$ das entregas, esse excedente foi de até $\mathrm{R} \$ 484$. A análise sobre os custos de força de trabalho alocados aos produtos possibilitou perceber o impacto que a não alocação de toda a força de trabalho em entregas bem definidas provoca no surgimento de excedentes de custos.

Primeiro, foi possível perceber que, independentemente da área, é possível mapear entregas das mais complexas, que envolvem equipes alocadas durante todo o ano, às entregas mais rotineiras, que envolvem inclusive atividades automatizadas. Com o esforço em mapear entregas fundamentais para cada área, a sobra pode ser considerada excedente de força de trabalho não alocada, o que pode onerar o núcleo de atividades principais do órgão.

Além disso, ao considerar salários, os custos de entregas semelhantes começam a ficar bem díspares. Essa situação sugere que, além da alocação adequada quanto ao número, pesquisas posteriores podem analisar o custo da alocação de carreiras custosas em atividades menos complexas. 


\subsection{Desempenho das áreas}

Um ranking para avaliação de desempenho por meio de análise fatorial foi gerado a partir das variáveis selecionadas. Identificou-se resultado globalmente significativo conforme o teste de esfericidade Bartllet e a estatística KMO. A partir do resultado do teste de esfericidade (Bartlett test of sphericity $=33265.310^{* * *}$ ), é possível rejeitar H0, que o modelo não é estatisticamente relevante globalmente. No mesmo sentido, o teste KMO (0.778) aponta para um bom nível de correlações de Pearson.

Os resultados dos testes permitem ir adiante com a análise fatorial, passando à geração dos componentes com suas respectivas variâncias e correlações. A partir dos componentes, geram-se os fatores e seus respectivos vetores e variância. Os fatores gerados associados às variáveis originais com suas cargas fatoriais foram gerados e a análise fatorial gerou um conjunto de quatro fatores capazes de agrupar as variáveis a partir dos seus níveis de correlação, apresentando comportamentos comuns dentro de cada um dos fatores.

A otimização dos resultados da análise é possível a partir dos métodos rotacionais ortogonais. O objetivo de todos os métodos de rotação é simplificar as linhas e colunas da matriz fatorial para facilitar sua interpretação. Em uma matriz fatorial, as colunas representam os fatores e cada linha corresponde às cargas de uma variável ao longo dos fatores (HAIR et al., 2009). Utilizou-se o método VARIMAX, que simplifica as colunas da matriz fatorial, maximizando as somas das variâncias das cargas da matriz.

A comparação entre a matriz não rotacionada e a rotacionada, a partir do método VARIAMAX, e suas respectivas cargas fatoriais foi realizada e, adotando os resultados da nova matriz rotacionada, os escores apresentados para os fatores por variável original são: 
Tabela 4 | Escores dos fatores por variável original

\begin{tabular}{|c|c|c|c|c|c|c|c|c|c|}
\hline Variable & Factor1 & Factor2 & Factor3 & Factor4 & Variable & Factor1 & Factor2 & Factor3 & Factor4 \\
\hline $\begin{array}{l}\text { Qtd_- } \\
\text { servidores }\end{array}$ & 0.11795 & -0.03816 & -0.00301 & 0.04375 & feriados & 0.02016 & -0.052 & 0.29805 & -0.02762 \\
\hline $\begin{array}{l}\text { Qtd__ } \\
\text { servidores } \\
\text { _dime }\end{array}$ & 0.11924 & -0.04229 & 0.00526 & 0.03199 & ictsj & 0.01655 & -0.04527 & 0.29803 & -0.00319 \\
\hline Esforc_total & 0.11913 & -0.04331 & -0.00057 & 0.02763 & $\begin{array}{l}\text { valor_kj__ } \\
\text { maior }\end{array}$ & -0.07591 & 0.28627 & 0.00845 & 0.01081 \\
\hline $\begin{array}{l}\text { Esforc_- } \\
\text { alocado }\end{array}$ & 0.10482 & -0.01355 & 0.01301 & 0.04891 & $\begin{array}{l}\text { valor_kj__ } \\
\text { menor }\end{array}$ & -0.0747 & 0.27296 & -0.00876 & -0.00978 \\
\hline Custo_total & 0.16255 & -0.15814 & -0.04093 & -0.07705 & valor_mj & -0.01658 & 0.10625 & 0.04433 & 0.42829 \\
\hline $\begin{array}{l}\text { Custo_- } \\
\text { alocado }\end{array}$ & 0.15767 & -0.14727 & -0.0448 & -0.07683 & valor_pj & 0.0272 & -0.04136 & -0.01295 & 0.16777 \\
\hline Custo_dime & 0.15034 & -0.13046 & 0.00618 & -0.08155 & $\begin{array}{c}\text { valor_pj__ } \\
\text { maior }\end{array}$ & 0.04725 & 0.09821 & -0.0202 & 0.0933 \\
\hline Qtd_entrega & -0.01339 & 0.10385 & 0.04377 & 0.42714 & $\begin{array}{l}\text { valor_q_ } \\
\text { estimado }\end{array}$ & 0.10301 & -0.01426 & 0.06946 & -0.00158 \\
\hline absenteismo & 0.01809 & -0.06084 & -0.05886 & 0.00653 & $\begin{array}{l}\text { valor_q_ } \\
\text { real }\end{array}$ & 0.1309 & -0.06944 & -0.01661 & 0.01012 \\
\hline $\begin{array}{l}\text { ativ__ } \\
\text { educativas }\end{array}$ & 0.06981 & -0.06908 & 0.11283 & -0.08538 & valor_tj & 0.05241 & -0.11326 & -0.24114 & -0.15653 \\
\hline $\begin{array}{c}\text { valor_exp_kj_ } \\
\text { maior }\end{array}$ & -0.09567 & 0.3212 & 0.02473 & 0.06318 & $\begin{array}{l}\text { valor_tj_ } \\
\text { maior }\end{array}$ & -0.05183 & 0.20993 & 0.28113 & 0.01264 \\
\hline $\begin{array}{l}\text { valor_exp_- } \\
\text { multi_tj_kj }\end{array}$ & -0.07644 & 0.29004 & -0.00652 & 0.02136 & - & - & - & - & - \\
\hline
\end{tabular}

Fonte: elaborado pelos autores.

A partir da adequação da análise fatorial e com a geração dos escores dos fatores, é possível a listagem dos desempenhos mensais das áreas para comparação com os recursos a elas alocados, também mensalmente. Os escores podem ser obtidos a partir da multiplicação dos fatores com os coeficientes da matriz rotacionada, a partir da seguinte equação:

$$
\text { Ranking }=f 1 \cdot 0,4110+f 2 \cdot 0,1759+f 3 \cdot 0,1322+f 4 \cdot 0,1098
$$


Os resultados dos 486 elementos analisados mostram que, no geral, áreas em que foram alocados mais recursos em termos de gastos com pessoal apresentaram melhor desempenho a partir da análise fatorial. Os 50 melhores desempenhos mensais ficaram também entre as 112 áreas que tiveram maiores montantes de valores empregados em pessoal. Como consequência, a correlação entre o coeficiente do ranking da análise fatorial e o montante de recursos empregados em pessoal, mensalmente, em cada área, foi de 0,81 , o que representa um elevado grau de correlação entre as duas variáveis.

Outra interessante observação diz respeito a elementos associados à CGU, que ocuparam as 59 primeiras posições. Cabe relembrar que esse órgão apresentou possibilidade de redução de $30 \%$ da força de trabalho nos anos analisados quando do resultado do dimensionamento. Contudo, como na elaboração do ranking a partir da análise fatorial foram considerados apenas os meses nos quais houve alocação de pessoal em qualquer nível ou houve dimensionamento de pessoal, essas áreas, mesmo superdimensionadas, ainda apresentaram bom desempenho mensal frente aos outros elementos avaliados (áreas avaliadas mensalmente).

Essa situação mostrou que, quando a força de trabalho está alocada nas entregas mapeadas e a área passa por processo de dimensionamento, áreas que antes apresentavam problemas de elevada alocação de força de trabalho em atividades residuais ficaram bem posicionadas quanto ao desempenho mensal medido a partir de ranking elaborado por análise fatorial. Nos 50 melhores elementos, por exemplo, a média de alocação mensal da força de trabalho foi de $93 \%$.

Os resultados obtidos corroboram as hipóteses de pesquisa levantadas no referencial teórico, de que as organizações não se encontram no ponto ótimo da relação custo-benefício dos serviços prestados. Portanto, baseado na teoria da escolha racional, a busca pelo número ótimo de trabalhadores para atingir a maximização da eficiência pôde ser calculada pelo DFT. Evidenciaram-se os custos excedentes decorrentes da não alocação de todo esforço disponível em entregas mapeadas. Identificou-se ainda força de trabalho em atividades residuais, o que indica a possibilidade de excesso de servidores em determinadas áreas. Todas as constatações possibilitam a geração de economia de recursos com a otimização da alocação da força de trabalho. 
Assim, à luz das teorias tratadas no referencial teórico e dos estudos anteriores, os resultados encontrados no presente estudo vão ao encontro de estudos anteriores (SAntos, 1998; Oliveira et al., 2007; Serrano et al, 2018; Mendes; Martins; Serrano, 2020), pois foram identificados custos excedentes e a possibilidade de geração de economia com base em uma nova forma de alocação da força de trabalho.

\section{Considerações finais}

A presente pesquisa se debruçou sobre o exame de três das vertentes levantadas: i) a atuação eficiente a partir da alocação de pessoal em quantidade adequada; ii) alocação de força de trabalho a partir de um enfoque de entregas realizadas; e iii) o custo da ineficiência na alocação e no dimensionamento da força de trabalho. Em todas essas vertentes, o objetivo foi o mesmo: evitar desperdícios.

O dimensionamento da força de trabalho, instrumento presente na realidade do setor privado, assume papel importante em cumprir esse objetivo de evitar desperdícios e oferecer a possibilidade de maior abrangência de serviços públicos de qualidade. Um modelo de dimensionamento leva em conta a análise da demanda por serviços públicos, da disponibilidade da força de trabalho e da capacidade das equipes. Com essas informações, é possível fazer uma conciliação mais adequada entre as atividades que são esperadas de determinada área e a disponibilização de força de trabalho em nível suficiente. A realidade da administração pública é a contratação e a alocação de servidores: i) por casos de reposição de força de trabalho; ou ii) por necessidade pontual de prestação de eventual serviço criado, mesmo que ele não seja definitivo (FONTAINHA et al., 2014).

A análise com 22 áreas, de três órgãos, envolvendo 689 servidores, mostrou um caminho bastante promissor no uso eficiente da força de trabalho, ganhando ainda mais relevância a partir da dificuldade atual de se contratar, tendo em vista o estabelecimento de teto para os gastos públicos a partir da PEC no 95/2016. Com a reforma constitucional, a administração pública está proibida de aumentar seus gastos além da inflação.

A primeira conclusão do trabalho refere-se à possibilidade de tornar as entregas do serviço público mais objetivas a partir de uma definição formal. Dessa forma, foi possível 
mapear 571 entregas para as 22 áreas analisadas. A definição de entregas foi importante inclusive no sentido de evidenciar como cada atividade contribui com a cadeia de valor de cada área.

Também foi possível, com aplicação de questionários e grupos focais, atribuir quanto de esforço de cada servidor foi atribuído a cada uma das entregas mapeadas. Essas informações, associadas aos custos com a força de trabalho, permitiram a verificação do custo da entrega realizada.

Com essas informações, foi possível em um primeiro momento identificar custos excedentes apenas com a não alocação de todo esforço disponível em entregas mapeadas, lembrando que um dos grandes objetivos da pesquisa foi levantar o máximo de entregas possíveis. Na CGU, foram $\mathrm{R} \$ 81,9$ milhões $(43,5 \%)$ alocados em atividades residuais nos dois anos analisados; na AGU, esse valor foi de R\$ 17 milhões (30\%) para os três anos analisados; e, no ME, esse valor foi de $\mathrm{R} \$ 7,8$ milhões (20\%) também para os três anos analisados. Esses valores são materiais e evidenciam que muito da força de trabalho ainda se perde em atividades que a própria administração ainda não reconhece como fundamental para sua cadeia de valor. Ademais, demonstra-se espaço para redução de custos e possibilidade de aumento da quantidade de serviços prestados.

Além da possibilidade de redução de custos, o fato de existir tanta força de trabalho em atividades residuais traz indícios de que existe a possibilidade de excesso de servidores em determinadas áreas. Esse indício foi confirmado com o modelo de dimensionamento adotado. Na CGU, nos dois anos analisados, foram encontrados mais de $30 \%$ de excesso de servidores lotados. Na AGU, o excesso de servidores foi superior a $35 \%$. No ME, a constatação foi distinta, pois em um dos anos foi observada ausência de servidores em número suficiente para o atendimento da demanda por serviços. Essa constatação também é nociva, pois indica que existe demanda reprimida, com possível demora na prestação de serviço público necessário.

Esses excessos provocaram um segundo tipo de excedente de custo decorrente da superlotação de algumas áreas. Na CGU, por exemplo, a adequação da lotação ganha contornos ainda mais relevantes em decorrência do custo elevado do servidor de uma carreira de Estado. Na AGU e no ME, esses excedentes também foram observados. 
Ao se eliminarem meses nos quais não houve alocação de recursos às entregas ou não houve dimensionamento, algumas áreas com baixa alocação de recursos ficaram bem posicionadas no ranking de desempenho elaborado a partir de análise fatorial.

Os números levantados mostram o quanto a gestão adequada dos recursos públicos pode ajudar na redução dos desperdícios e, por consequência, na correta condução da política fiscal, já que os gastos com pessoal são tão importantes. Essas medidas ganham ainda mais relevância em um contexto de escassez de recursos.

As economias mostraram-se relevantes em uma pequena amostra de áreas da administração pública federal. O desafio é reproduzir a iniciativa em outras esferas e considerando outros tipos de gastos. A presente pesquisa lançou luz sobre o principal gasto ativo de custeio do Governo Federal, mas novas pesquisas podem incorporar outros gastos de custeio, o que representa um grande desafio tendo em vista a fragilidade dos sistemas de gestão federal. Outrossim, uma outra boa contribuição seria investigar como um regime de metas de entrega poderia aumentar a eficiência dos serviços prestados, impactando inclusive na tempestividade de atendimento das necessidades por serviços públicos, que é outro problema que a administração pública enfrenta.

\section{Referências}

ABRUCIO, Luiz Fernando. Os avanços e os dilemas do modelo pós-burocrático: a reforma da administração pública à luz da experiência internacional recente. In: PEREIRA, Luiz Carlos Bresser; SPINK, Peter. Reforma do Estado e administração pública gerencial. Rio de Janeiro: FGV, 2003.

ABrucio, Luiz Fernando; Pedrotı, Paula; Pó, Marcos V. A formação da burocracia brasileira: a trajetória e o significado das reformas administrativas. In: LoUREIRO, M. R.; ABRUCIO, F.; PACHECO, Regina R. (Orgs.). Burocracia e política no Brasil: desafios para a ordem democrática no século XXI. Rio de Janeiro: FGV, 2010.

Alvarenga-Netto, C. A. Proposta de modelo de mapeamento e gestão por macroprocessos. Tese de Doutorado. Universidade de São Paulo. São Paulo, 2004.

AvelLaneda, Claudia N.; Gomes, Ricardo Corrêa. Is small beautiful? Testing the direct and nonlinear effects of size on municipal performance. Public Administration Review, v. 75, n. 1, p. 137-149, 2015. 
BAnco Mundial. Um ajuste justo: análise da eficiência e equidade do gasto público no Brasil. Brasil revisão das despesas públicas. Brasil: Grupo Banco Mundial, 2017.

CAVAlCANTE, P.; CARVAlho, P. Profissionalização da burocracia federal brasileira (1995-2014): avanços e dilemas. Revista de Administração Pública, v. 51, n. 1, p.1-26, 2017.

ChagAs, Anivaldo T. R. O questionário na pesquisa científica. Revista Administração. 2000. Disponível em: <https://moodle.ufsc.br/pluginfile.php/1255609/mod_resource/content/0/0_ questionariona_pesquisacientifica.pdf $>$.

CHOUdHURY, Enamul. Workforce planning in small local governments. Review of Public Personnel Administration, n. 27, p. 264-280, 2007.

CoRRAR, Luiz J.; PAUlo, Edilson; Dias Filho, José M. Análise multivariada para os cursos de administração, ciências contábeis e economia. São Paulo: Atlas, 2017.

CunHA, Raissa et al.. O que é planejamento da força de trabalho. In: SerRano, André et al. Dimensionamento na administração pública federal: uma ferramenta do planejamento da força de trabalho. Brasília, 2018.

DIAS, C. A. Grupo focal: técnica de coleta de dados em pesquisas qualitativas. Revista Informação \& Sociedade: Estudos, v. 10, n. 2, p.141-158, 2000.

Dickinson, H.; SUlLIVAN, H.; HeAD, G. The future of the public service workforce: a dialogue. Australian Journal of Public Administration, v. 74, n. 1, p. 23-32, 2015.

ERnSt, Andreas; JIANG, Houyuan; KRISHnamoorthy, Mohan; SIER, David. Staff scheduling and rostering: a review of applications, methods and models. European Journal of Operational Research, n. 153, p. 3-27, 2004.

EVEBORN, P.; RonNQVIST, M. Scheduler a system for staff planning. Annals of Operations Research, v. 128, n. 1-4, p. 21-45, 2004.

FontAInHA, Fernando de Castro et al. Processos seletivos para a contratação de servidores públicos: Brasil, o país dos concursos? Relatório de pesquisa. Rio de Janeiro: Direito Rio, 2014.

Franco, Vithor; SerRano, André. O que é dimensionamento da força de trabalho. In: SerRano, André et al. Dimensionamento na administração pública federal: uma ferramenta do planejamento da força de trabalho. Brasília, 2018.

GAIDZINSKI, R., R. Dimensionamento de pessoal de enfermagem em instituições hospitalares. Tese de Doutorado. São Paulo: Escola de Enfermagem, Universidade de São Paulo, São Paulo, Brasil, 1998.

GonçALVES, José Ernesto Lima. As empresas são grandes coleções de processos. Revista de Administração de Empresas, v. 40, n. 1, p. 6-9, 2000.

GoODMAN, D.; FRENCH, Edward; BATTAGLIO Paul. Determinants of local government workforce planning. The American Review of Public Administration, v. 45, n. 2, p. 135-152, 2015. 
GUERRA, A. R. Arranjos entre fatores situacionais e sistema de contabilidade gerencial sob a ótica da teoria da contingência. Dissertação de Mestrado. Universidade de São Paulo. São Paulo, 2007.

HAIR Jr., J. F. et al. Análise multivariada de dados. Porto Alegre, Bookman, 2009.

HeLton, K. A.; JACKSON, R. D. Navigating Pennsylvania's dynamic workforce: succession planning in a complex environment. Public Personnel Management, v. 36, n. 4, p. 335-347, 2007.

InStItUto de Pesquisa Econômica Aplicada. Atlas da violência. Brasília, 2019. Disponível em: < https://www.ipea.gov.br/portal/index.php?option=com_content\&view=article\&id=34784 >.

JACOBSON, W. S. Preparing for tomorrow: a case study of workforce planning in North Carolina municipal governments. Public Personnel Management, n. 39, v. 4, p. 353-377, 2010.

LI, Yongjian; CHEN, Jian; CAl, Xiao Qiang. A integrated staff-sizing approach considering feasibility of scheduling decision. Annals OR, n. 155, p. 361-390, 2007.

LIBERTI, José María; Petersen, Mitchell A. Information: hard and soft. The Review of Corporate Finance Studies, v. 8, n. 1, p. 1-41, mar. 2019.

Mendes, N.; Martins, P.; Serrano, A. O dimensionamento da força de trabalho pela ótica de teorias científicas: uma análise à luz das teorias institucional e da firma. In: SERRANO, A.; MENDES, N. Dimensionamento na Administração Pública Federal: possibilidades de aplicação e potencial de alcance. Brasília, 2020.

MolL, Jodie; HoQUE, Zahirul. Rational choice theory. In: HOQUE, Zahirul. Methodological issues in accounting research: theories and methods. Spiramus, 2006.

MORGESON, P.; FREDERICK A.; CAMPION, Michael. Accuracy in job analysis: toward an inferencebased model. Journal of Organizational Behavior, v. 21, p. 819-827, 2000.

OliveIRA, A. G.; BIANCHINI, D.; ABBADE, M. L. F. Métricas para dimensionar recursos humanos nos centros de operações de redes. In: ANAIS Do 25 SIMPósIO BRASILEIRO DE REDES DE COMPUTADORES e Sistemas Distribuídos. Belém do Pará, p. 1091-1096, 2007.

ORGANIZAÇÃO DE COOPERAÇÃO E DE DESENVOLVIMENTO ECONÔMICO. Government at a Glance 2017. Brasília, 2017.

PereIRA, Delciene A. O. Gestão da informação associada ao processo de dimensionamento de força de trabalho: estudo de caso no Ministério da Saúde. Dissertação de Mestrado. Universidade de Brasília. Brasília, 2016.

PerRocA, M. G.; GAIDZINSKI, R. R. Sistema de classificação de pacientes: construção e validação de um instrumento. Rev Esc Enferm USP, n. 32, v. 2, p. 153-68, 1998.

RiBeiRo, R. R. M.; LEITE, R. M.; CROZATTI, J. A racionalidade e processo decisório: algumas reflexões teóricas. Enfoque Reflexão Contábil, n. 25, v. 1, p. 15-24, 2006.

SALVADOR, M.; RIBA, C. A externalização como estratégia da gestão de serviços públicos locais. Revista de Administração Pública, v. 51, n. 4, p. 633-652, 2017. 
SAmpieri, R. H.; Collado, C. F.; LUcio, P. B. Metodologia de pesquisa. São Paulo: Mcgrawhill, 2006.

SANCHEZ, J. I.; LEVINE, E. L. The analysis of work in the 20th and 21st centuries. In: ANDERSON, N. et al. (Eds.). Handbook of industrial, work and organizational psychology. Thousand Oaks: Sage Publications, 2002.

SAntos, A. M. B. Produtividade de mão de obra e do capital investido na Petrobrás: sua relação com o dimensionamento da força de trabalho. Dissertação de Mestrado. Fundação Getúlio Vargas. Rio de Janeiro, 1998

SERRANO, A. L. M. Dimensionamento da força de trabalho no setor público: modelo qualiquantitativo aplicado. In: ANAIS Do IX CONGRESSO CONSAD DE Gestão Pública, 9, Brasília, 2016.

SERRANO, André et al. Dimensionamento da força de trabalho aplicado a uma organização do Poder Executivo federal. In: ANAIS Do XX SEMEAD, São Paulo, 2017.

Serrano, André; Franco, Vithor. Metodologia e modelo para dimensionamento. In: SerRano, André et al. Dimensionamento na administração pública federal: uma ferramenta do planejamento da força de trabalho. Brasília, 2018.

SotILLE, Mauro et al. Gerenciamento do escopo em projetos. Brasília: FGV, 2016.

TAYLOR, Mary Jean et al.; Staffing and retention in public safety communication centers. Daytona Beach: APCO Project RETAINS, 2005. Disponível em: <https://retains.apcointl.org/pdf/Effective_ Practices_Guide.pdf>.

TorRes, M. C. G. et al. Cadeia de valor: os benefícios do alinhamento entre a estratégia governamental e a operacionalização de seus processos. In: VI CONGRESSO CONSAD DE GESTÃo PúBlicA. Anais... Brasília, 2013.

TRIBUNAL DE CONTAS DA UNIÃO. Levantamento integrado de governança organizacional pública: ciclo 2017. Brasília, 2018. Disponível em: <https://portal.tcu.gov.br/governanca/ governancapublica/organizacional/levantamento-2017>.

Vianna, Cid Manso de Mello et al. Modelos econométricos de estimativa da força de trabalho: uma revisão integrativa da literatura. Physis, v. 23, n. 3, p. 925-950, 2013.

\section{Heitor Silveira Freitas}

(iD http://orcid.org/0000-0003-0365-9217

Mestre em Ciências Contábeis pela Universidade de Brasília (UnB) e Especialista em Auditoria Financeira pelo ISC-TCU/UnB.

E-mail: silveiraf@tcu.gov.br

\section{André Luiz Marques Serrano}

(D) http://orcid.org/0000-0001-5182-0496

Doutor em Economia pela PPGE/FACE/ UNB (2011). Mestre em Economia pela Universidade de Brasília (UnB) e Bacharel em Contabilidade PPGC/FACE. Professor Associado da Engenharia de Produção EPR/FT. E-mail: andrelms@unb.br 


\section{Lucas Oliveira Gomes Ferreira}

(iD) http://orcid.org/0000-0002-8734-4740

Doutorando pelo PPGCONT - UnB. Professor Adjunto do Departamento de Ciências Contábeis e Atuariais da Universidade de Brasília (UnB).

E-mail: lucasoliveira@unb.br 